\title{
EDITORIAL
}

\section{YEARS OF THE DOUBLE HELIX Could Watson and Crick have envisioned the true impact of their discovery?}

\author{
Ilene Sussman \\ VHL Alliance, Inc, Boston, Massachusetts, USA \\ Correspondence should be addressed to I Sussman: Ilene.sussman@vhl.org \\ This paper is part of a thematic review section celebrating 65 Years of the Double Helix. The guest editors for this section were Charis Eng, William \\ Foulkes and Jérôme Bertherat.
}

\begin{abstract}
Landmark scientific findings are applauded. However, at the time of discovery, the future impact that these types of new knowledge might have on patients is not foreseen. This article discusses how unraveling the structure of DNA has advanced medical treatment, particularly for patients with rare diseases. In addition, each new scientific discovery brings with it the emotion of hope for improved diagnosis and treatment, as well as enhanced outcomes and increased longevity for patients facing a life-long disease.
\end{abstract}

\author{
Key Words \\ - von Hippel-Lindau \\ - rare diseases \\ - DNA structure \\ - patient voice
}

- hope
James Watson and Francis Crick excitedly shared the importance of their February 28, 1953 breakthrough on the structure of DNA at their regular lunch with colleagues that day. The 'secret of life' had been uncovered. Crick further acknowledged his excitement that evening with his wife. However, could the team have truly understood the impact of their work and where it would take the scientific community in a mere 65 -year period? Could they have dreamed of opening the door to the modern field of genetics that today includes DNA sequencing, the Human Genome Project, medical and recreational genetic testing, genetic cloning and gene therapy? What about the necessity of a new field in health care, namely, genetic counseling? Certainly, they could never have envisioned the moral and ethical issues that would arise from unraveling DNA's double helix structure. From the perspective of a patient with a genetic disease, particularly one with a rare genetic disease, it is hard to even conceive that Watson and Crick could have imagined that their discovery would introduce the basic emotion of hope.

Von Hippel-Lindau, or VHL, is a rare genetic cancer syndrome resulting in tumors growing in 10 different organs: kidney, spine, brain, retina, adrenal glands, pancreas, inner ear, reproductive tract, liver and lung. Patients with VHL face a series of tumors, along with surgeries to remove the lesions, throughout their lives. A disease such as VHL not only results in a physical toll, but it also negatively impacts the emotional wellbeing of patients along with their families and loved ones (Lammens et al. 2010, 2011).

For years, families with VHL understood that their offspring were at a greater risk of inheriting their medical condition of unending tumor growth. It was the 1993 sequencing of the VHL gene located on the short arm 
of chromosome 3 (3P25-P26) by Latif et al. (1993) that initiated the long, and seemingly endless, journey of hope.

Understanding the genome structure opened the door to genetic testing and equally importantly, geneinformed cancer risk assessment and management. Using Sanger sequencing, genetic confirmation of VHL became possible. Next-generation sequencing, the more recent advancement in genetic testing, with increasing detection sensitivity allows for VHL detection in patient with the mosaic form of the disease.

Patients and their medical teams can now be attuned to VHL; taking (and developing) measures to identify tumors early and excising them, so called enhanced surveillance leading to the earliest of diagnosis and curative surgery. Offspring can be tested at a young age (because some of the tumors do occur that young) so that surveillance can be initiated when they are still young and before the risk of neoplasias rise. Embryonic genetic testing enables parents to know whether or not their unborn child will have VHL. The development of IVF combined with preimplantation genetic diagnosis (PGD) now allows parents to avoid passing the disease onto their offspring, if they so desire.

These new technologies demand a high level of understanding and careful consideration by patients because the implications are enormous. While the knowledge of a pre-existing condition currently does not play a role in issues related to health insurance, they do greatly impact a patient's ability to secure life insurance. They also play a tremendous role in family planning, a decision that should only be made by the perspective parent(s). Thus, the need for genetic counseling - a growing health care specialty and field with an increasing demand for trained professionals. A qualified genetic counselor can help educate patients and families of their risk of carrying the defective VHL gene and the impact it may have on existing family members as well as future offspring. They can describe family planning options, working with individuals or couples to decide what approach is best for them - a decision that is uniquely their own.

The advancement of technology accompanied by lower cost and increased accessibility has resulted in the current interest in 'recreational' genetic testing; just lick a swab and learn your genetic code. This is a process independent of medical input, advice, or counseling. What are the emotional implications of this trend? How does one respond or feel when a serious genetic disorder is uncovered in the process of learning about their genetic make-up and family ancestry? Should genetic counseling be required for this recreational genetic testing?

The expanded field of genomics also raises ethical issues. How should it be used, by whom and for what purpose? The field of bioethics grapples with the unanswered dilemma of 'Are we playing god'? A question retrospectively associated with the Eugenics Movement, a dark chapter in scientific history.

In contrast, the discovery of the structure of DNA opened the door for gene-informed therapy, ie, gene editing (see review on gene editing in this issue). Once a pipe dream, it is a growing technology with nearly 20 treatments currently approved by the FDA. Most relevant to VHL patients is Sparks Therapeutics 1997 approval of Luxturna, a genetic therapy for a rare form of inherited vision loss. It is every VHL patient's dream that such technology can be transferred to treat or prevent blindness caused by VHL-related retinal hemangiomas and, ultimately, to prevent all VHL manifestations. The recent advances of CRISPR are inspiring to patients raising the hope of curing VHL on a genetic level, removing the need for surgical and yet-to-be discovered pharmacological interventions.

The significance of the date on which Watson and Crick discovered DNA's double helix cannot be overlooked, February 28, 1953. Ironically, five and a half decades later, the last day of February was declared as a Rare Disease Day; a day to acknowledge and raise awareness among the general public and decision-makers of rare diseases and their impact on patients' lives. While one in 10 people suffer from a rare disease, the impact is much larger when one includes family and friends who are 'indirectly' impacted by their rare, often genetic medical condition.

Perhaps then, in conclusion, the best way to honor the 65th anniversary of unraveling the structure of DNA, may be to rededicate the pyridines and pyrimidines to Health, Optimism, Perseverance, and Encouragement. By doing so, we will also be honoring the feelings of hope further ignited by each scientific breakthrough by anyone person suffering from a genetic disorder.

The author would like to acknowledge the enormous contribution of the often overlooked researcher Rosaline Franklin who helped discover the DNA structure.

\section{Declaration of interest}

The author declares that there is no conflict of interest that could be perceived as prejudicing the impartiality of this editorial. 


\section{Funding}

This work did not receive any specific grant from any funding agency in the public, commercial or not-for-profit sector. This work was supported by the generous contribution of VHL patients, families and friends.

\section{References}

Lammens CR, Bleiker EM, Verhoef S, Hes FJ, Ausems MG, MajoorKrakauer D, Sijmons RH, van der Luijt RB, van den Ouweland AM, Van Os TA, et al. 2010 Psychosocial impact of Von Hippel-Lindau disease: levels and sources of distress. Clinical Genetic 77 483-491. (https://doi.org/10.1111/j.1399-0004.2010.01333.x)

Lammens CR, Bleiker EM, Verhoef S, Ausems MG, Majoor-Krakauer D, Sijmons RH, Hes FJ, Gómez-García EB, Van Os TA, Spruijt L, et al. 2011 Distress in partners of individuals diagnosed with or at high risk of developing tumors due to rare hereditary cancer syndromes. Psycho-oncology 20 631-638. (https://doi.org/10.1002/ pon.1951)

Latif F, Tory K, Gnarra J, Yao M, Duh FM, Orcutt ML, Stackhouse T, Kuzmin I, Modi W, Geil L, et al. 1993 Identification of the von Hippel-Lindau disease tumor suppressor gene. Science 260 1317-1320. (https://doi.org/10.1126/science.8493574)

Received in final form 19 March 2018 Accepted 21 March 2018
(C) 2018 Society for Endocrinology Published by Bioscientifica Ltd. Printed in Great Britain 